\title{
Considerations about an experimental model of chronic metabolic acidosis in rats
}

\author{
A. A. S. Albuquerque ${ }^{a}$ (D), A. C. Celloto ${ }^{a}$ (D), W. M. Silva ${ }^{a}$ (D), L. S. Mateus ${ }^{a}$ \\ and P. R. B. Evora ${ }^{a *}$ (iD \\ ${ }^{a}$ Divisão de Cirurgia Torácica e Cardiovascular, Departamento de Cirurgia e Anatomia, Faculdade de Medicina de Ribeirão \\ Preto - FMRP, Universidade de São Paulo - USP, Av. Bandeirantes, 3900, CEP 14048-900, Ribeirão Preto, SP, Brasil \\ *e-mail: prbevora@fmrp.usp.br
}

Received: August 29, 2019 - Accepted: September 17, 2019 - Distributed: February 28, 2021

(With 2 figures)

During the last decades, several studies have been published and have led to the data collection on the acid-base disorder and endothelial function (Celotto et al., 2008). It was determined that extracellular acidification induced by $\mathrm{HCl}$ (7.4 to 6.5) promotes NO, K (ATP) and SK-mediated vasodilation $(\mathrm{Ca})$, and perhaps other $\mathrm{K}(+)$ channels in the isolated thoracic aorta of the rat (Celotto et al., 2011). The scientific literature has many reports on acid-base balance and endothelium function, but these concepts are unclear about acid-base disorders and their relationship to the three known mechanisms of endothelium-dependent vascular reactivity: nitric oxide (NO/cGMP-dependent), prostacyclin (PGI2/cAMP-dependent) and hyperpolarization.

Another study from our research group aimed to study the in vitro vascular responses induced by hypercapnic extracellular acidification (AH), as well as the endothelium-dependent mechanisms that are involved in the responses. It has been concluded that: 1) AH causes endothelium-dependent relaxation; 2) Indomethacin failed to block this relaxation, but the limitation of the method does not allow discarding some prostanoid paper; 3) Relaxation of the HA vessel is mediated via cGMP/NO and; 4) Hyperpolarization occurs by the action of the potassium channels SKCa, $\mathrm{KATP}$, and $\mathrm{Kv}$, without depending on BKCa channels (Nadai et al., 2014).

Also, our studies investigated the in vivo effects of acute metabolic acidosis (AMA) and chronic metabolic acidosis (CMA) on hemodynamic parameters showing that AMA, but not CMA, potentiates the reduction of blood pressure induced by acetylcholine (Celotto et al., 2016).

We investigated to advance the studies about the effects of chronic metabolic acidosis on the endothelium-dependent reactivity of rat carotid artery. Also, as complementary studies, hemodynamic and ventilatory parameters were carried out, as well as the mechanisms involved in this response. The experimental animals were male Wistar rats, mean age of 70-90 days (250-300 g), from the Central Biotherium of the Ribeirão Preto Campus, University of São Paulo (USP). The animals were kept in a light-dark cycle of $12 / 12$ hours, at constant temperature $\left(22{ }^{\circ} \mathrm{C}\right)$, and with free access to water and food. The number of animals for each protocol was $6(n=6)$, which is necessary for statistical analysis according to the experience of our laboratory in this type study and based on the literature of the area. The procedures with the animals, as well as the experimental protocols of this study, were approved by the Ethics Committee on Animal Use (CEUA) of the University of São Paulo at Ribeirão Preto Medical School (protocol 23/2015), according to the Ethical Principles in Animal Experimentation of the Brazilian College of Animal Experimentation (COBEA). The rats were divided into pairs per box, daily they were heavy and had the solution and ration, ad libitum, measures, and exchanges.

Chronic metabolic acidosis was induced for 10 days by replacing water with a solution of $0.50 \mathrm{M}$ ammonium chloride for ten days. Animals of the acidosis group received ad libitum the diluted ammonium chloride solution in a solution of $0.03 \%$ artificial powdered juice. The animals in the control group received artificial juice powder. Also, a $0.02 \mathrm{M}$ ammonium chloride solution was gavaged with a volume of $1 \mathrm{~mL}$ during the 10 days to ensure that each animal ingested the minimum amount of solution, sufficient for the installation of the metabolic acidosis. Arterial blood samples were collected from the abdominal aorta artery of each animal. The biochemical measurements of $\mathrm{pH}$, partial carbon dioxide ( $\mathrm{pCO} 2$ ) arterial pressure and plasma concentration of bicarbonate ion (HCO3-) were performed by a previously calibrated Hemogasometria Gem Premier 3000 (Instrumentation Laboratory Co., Bedford, Massachusetts, USA) using the 150 GEM Premier iQM Instrumentation Laboratory Co., Bedford, Massachusetts, USA. Data were presented as a mean \pm standard error of the mean (SEM) ANOVA or two-way ANOVA, followed by the Bonferroni post-test, using GraphPad Prism version 4.0 (GraphPad Software Corporation, La Jolla, California, USA). The adopted level of significance was $\mathrm{p}<0.05$.

Chronic metabolic acidosis (CMA) induced by ammonium chloride $(\mathrm{NH} 4 \mathrm{Cl})$ reduced the $\mathrm{pH}$ to 7.17 (7.39 control), with levels of bicarbonate (HCO3) about $9.8 \mathrm{mmol} / \mathrm{L}(21.9 \mathrm{control} \mathrm{mmol} / \mathrm{L})$. Animals that received $\mathrm{NH} 4 \mathrm{Cl}$ also had lower weight gain during the study period. This reduction in weight gain could be due to a decrease in feed intake observed in these animals. The CMA induced by $\mathrm{NH} 4 \mathrm{Cl}$ through gavage infusions, and association of powdered juice (orange flavour), was more efficient than ad libitum oral feed. The experimental CMA model was reproducible emphasizing that the association of powdered juice (orange flavour) and gavage were excellent resources for the rat acid solution acceptance and allowing better results. These results are illustrated in Figure 1 and Figure 2. 

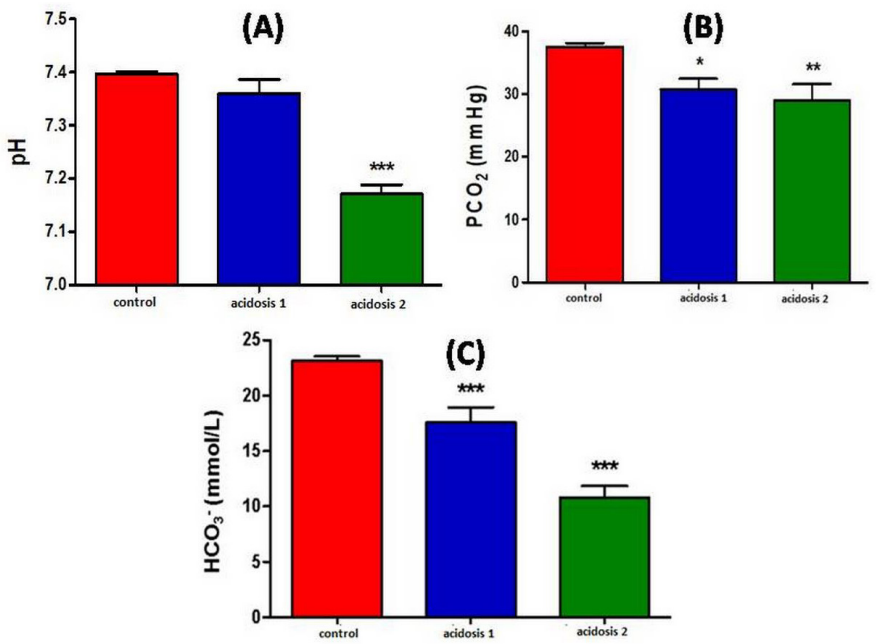

Figure 1. Effect of different treatments with $\mathrm{NH} 4 \mathrm{Cl}$ on: (A) $\mathrm{Ph}$; (B) $\mathrm{PCO} 2$, and; (C) blood bicarbonate. Acidosis 1 $(0.5 \mathrm{M} \mathrm{NH} 4 \mathrm{Cl}$ ad libitum); Acidosis $2(0.5 \mathrm{M} \mathrm{NH} 4 \mathrm{Cl}$ ad libitum $+0.02 \mathrm{M}$ gavage $)$. The data represent the mean $\pm \mathrm{SEM}$ $(\mathrm{n}=16), * * * \mathrm{p}<0.0001$ (control versus acidosis 1 and acidosis 2), One-Way ANOVA, Bonferroni post-test.
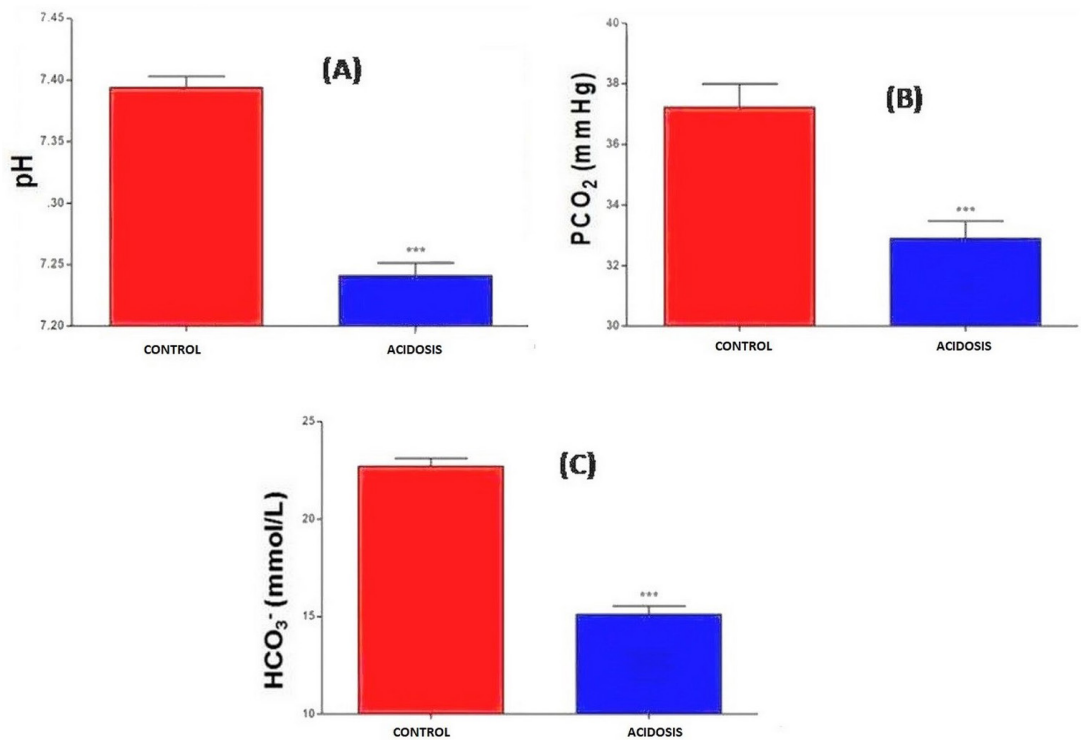

Figure 2. Effect of treatment with solution ad libitum $(\mathrm{NH} 4 \mathrm{Cl} 0.5 \mathrm{M})$ gavage $(0.02 \mathrm{M} \mathrm{NH} 4 \mathrm{Cl})$ on $(\mathrm{A}) \mathrm{Ph}$; $(\mathrm{B}) \mathrm{PCO}$, and; (C) bicarbonate. Data represent the mean $\pm \operatorname{SEM}(n=16), * * * p<0.0001$ (control versus acidosis), $t$ test.

This study has the purpose of standardization an experimental method of CMA induction, which can help investigators interested in study acid-base disorders.

\section{References}

CELOTTO, A.C., CAPELLINI, V.K., BALDO, C.F., DALIO, M.B., RODRIGUES, A.J. and EVORA, P.R., 2008. Effects of acid-base imbalance on vascular reactivity. Brazilian Journal of Medical and Biological Research, vol. 41, no. 6, pp. 439-445. http:// dx.doi.org/10.1590/S0100-879X2008005000026. PMid:18592120.

CELOTTO, A.C., FERREIRA, L.G., CAPELLINI, V.K., ALBUQUERQUE, A.A., RODRIGUES, A.J. and EVORA, P.R., 2016. Acute but not chronic metabolic acidosis potentiates the acetylcholine-induced reduction in blood pressure: an endothelium-dependent effect. Brazilian Journal of Medical and Biological Research, vol. 49, no. 2, pp. e5007. http://dx.doi. org/10.1590/1414-431x20155007. PMid:26648089.

CELOTTO, A.C., RESTINI, C.B., CAPELLINI, V.K., BENDHACK, L.M. and EVORA, P.R., 2011. Acidosis induces relaxation mediated by nitric oxide and potassium channels in rat thoracic aorta. European Journal of Pharmacology, vol. 656, no. 1-3, pp. 88-93. http://dx.doi.org/10.1016/j.ejphar.2011.01.053. PMid:21300058.

NADAI, T.R., SILVEIRA, A.P., MONTEIRO, A.S., CAMPOS, D.R., CARVALHO, M.T., ALBUQUERQUE, A.A., CELOTTO, A.C. and EVORA, P.R., 2014. Presentation of an experimental method to induce in vitro ("organ chambers") respiratory acidosis and its effect on vascular reactivity. Acta Cirurgica Brasileira, vol. 29 , no. 11 , pp. 711-714. http://dx.doi.org/10.1590/S010286502014001800003. PMid:25424290. 